\title{
Unravelling the contributions of social, environmental and genetic factors to health differences
}

\author{
Vence L. Bonham JD, Erin M. Ramos PhD MPH
}

$\infty \quad$ See related research paper by Kisely and colleagues, page 653 oday researchers seek to unravel the factors leading to the differences in health seen between people of different racial and ethnic backgrounds. But how do we explore all of the factors that may be involved without overstating any single one? This is the major challenge facing clinical and biomedical researchers who seek to understand and address racial and ethnic health disparities. In this issue of CMAJ, Kisely and colleagues ${ }^{1}$ investigate the rates of common, yet complex, health conditions in a community of African Nova Scotians.

In this retrospective cohort study, Kisely and colleagues used administrative billing databases to examine the incidence of circulatory disease, psychiatric disorders and diabetes in Preston, Nova Scotia, a predominately African Nova Scotian town. They report a number of disparities in health status. The age- and sex-standardized cumulative incidence rates of these 3 conditions were 13\%-43\% higher in Preston than in the rest of the province. In contrast, the incidence of these conditions in the 7 comparison communities with comparable household income, education, employment rate and proximity to hospital were similar to the rates in the rest of the province for circulatory disease and diabetes. The rates of psychiatric disorders were lower in the comparison communities than in Nova Scotia as a whole.

The authors should be congratulated for documenting these disparities and raising the question of why they exist. However, their interpretation of the results of the study may under-estimate the contribution of socio-economic factors because of the relatively crude measures of socio-economic status currently available. By accounting for measurable factors, such as median household income, unemployment and education, many researchers hope to reduce the potential for socio-economic status to confound results and often conclude that any remaining differences are because of genetics or unmeasured environmental factors. ${ }^{2}$ However, because socio-economic status is a broad, complex concept that is difficult to measure accurately, substantial residual confounding may still exist and may affect the validity of the results of the study. ${ }^{3}$

Socio-economic factors are multidimensional. In this study, measuring economic resources such as actual wealth and socio-economic conditions at the neighbourhood level would be desirable. Evidence suggests that a person's health can be influenced by the socio-economic characteristics of his or her neighbourhood, because people with similar individual- or household-level socio-economic characteristics can live in very different local environments. ${ }^{4}$ Thus, one may question the authors' conclusion that the higher inci-

\section{Key points}

- Large, well-designed, prospective population-based studies in diverse populations are needed to determine the causes of common, complex diseases.

- Socially identified racial and ethnic groups are not genetically distinct groups.

- Caution should be taken when assessing risk of disease using racial and ethnic labels.

- Developing better tools to accurately measure the social and physical environmental factors that influence disease should be a priority for the international biomedical research community.

- A 3-generation family health history can serve as a useful tool to identify patients at increased risk of common diseases.

dence of disease in Preston cannot be explained by socioeconomic characteristics and is instead a result of genetic, biological or other factors such as behavioural, psychosocial or environmental factors.

Current data refutes the notion that socially identified racial and ethnic groups like African Nova Scotians are genetically distinct, because no sharp genetic boundaries can be drawn between human populations. ${ }^{5,6}$ The concepts of race and ethnicity carry complex connotations that reflect culture, history, socio-economic and political status ${ }^{7}$ as well as an important connection to ancestral geographic origins. ${ }^{8}$ Selfidentified race and ethnic background correlate with genetic population groups ${ }^{9}$ but not necessarily with a person's distinct genetic background. There is more genetic variation within a single population than between different populations. ${ }^{6}$ Thus, although our understanding of human genetic variation and its correlation with disease is growing, a substantial debate continues surrounding the relation between genetic risk of disease and self-identified race and ethnic background.

An exciting promise of increasing genomic knowledge is its potential to facilitate personalized medicine. By determining individual genetic susceptibilities, both disease prevention and drug treatment can be tailored to individual patients. Technological and scientific advances are still insufficient to make sequencing a patient's genome to determine genetic risk of disease clinically feasible; however, a 3-generation family medical history can be readily collected using simple tools. ${ }^{10,11}$ Such tools provide better information for individualized care than the patient's racial or ethnic background. Most diseases

From the Social and Behavioral Research Branch, Division of Intramural Research (Bonham) and the Office of Population Genomics (Ramos), National Human Genome Research Institute, National Institutes of Health, Bethesda, Md. 
are the result of the interaction of multiple genetic and environmental factors that remain to be identified. ${ }^{12}$ Through their family history, however, patients have access to a free, well-proven and personalized genomic tool that captures the effects of many of these factors and can serve as the cornerstone for personalized disease prevention. ${ }^{13}$

Social and physical environment matter - it is the complex interplay of environmental and genomic factors that determine health and disease. Today we are developing new and improved measures of environmental exposures, ${ }^{14,15}$ which will provide important opportunities to investigate how the environment and the human genome interact to influence health. Well-characterized prospective population-based studies performed by interdisciplinary research teams that collect extensive genomic, biologic, social and environmental exposure data before the onset of disease will facilitate our understanding of these interactions. Residential segregation and quality of the neighbourhood ${ }^{16}$ as well as diet, health behaviours, education, social marginalization and experience of discrimination all influence health and health differences.

Despite a higher incidence of psychiatric diagnoses in Preston, Kisely and colleagues report that members of this community accessed fewer specialists for psychiatric disorders (incidence rate $0.75,95 \%$ confidence interval [CI] 0.62-0.89) and used public mental health services less often than people in Nova Scotia as a whole (incidence rate 0.56 , 95\% CI 0.45-0.68). This may suggest variation in treatment patterns and that even with universal health care, barriers exist to receiving treatment. Furthermore, in discussing universal health care and health disparities, Baxter recently stated that "it would be naive to believe that equal treatment at the point of care could obviate economic, educational and social inequities that, in some cases have affected our patients not just throughout their lives, but even in utero." 17

Unravelling the causes of health disparities is the responsibility of basic, clinical and social science researchers. Addressing these causes is the responsibility of policy makers, communities, clinicians and patients. In 2004, Francis S. Collins wrote: "To determine accurate risk factors for disease, we need to carry out well-designed, large-scale studies in multiple populations. Such studies must be equally rigorous in their collection of genetic and environmental data. If only genetic factors are considered, only genetic factors will be discovered." Kisley and colleagues have alerted the Canadian biomedical research community of disparities in the health of African Nova Scotians, challenging researchers to begin to critically examine these factors. The findings that result may guide new health interventions that can improve the health of racial and ethnic minorities throughout North America.

Competing interests: None declared

Contributors: Both of the authors were involved in the preparation of this manuscript and approved the final version submitted for publication.

Acknowledgements: This research was supported in part by the Intramural Research Program of the National Human Genome Research Institute, National Institutes of Health. The content of this article is solely the responsibility of the authors and does not represent any position or policy of the National Human Genome Research Institute, National Institutes of Health or Department of Health and Human Services.

We thank Dr. Teri A. Manolio for her helpful comments and suggestions on an early draft of this commentary.

\section{REFERENCES}

1. Kisely S, Terashima M, Langille D. A population-based analysis of the health experience of African Nova Scotians. CMAJ 2008;179:653-8.

2. Kaufman JS, Cooper RS. Race in epidemiology: new tools, old problems. Ann Epidemiol 2008;18:119-23.

3. Kaufman JS, Cooper RS, McGee DL. Socioeconomic status and health in blacks and whites: The problem of residual confounding and the resiliency of race. Epidemiology 1997;8:621-8.

4. Braveman PA, Cubbin C, Egerter S, et al. Socioeconomic status in health research one size does not fit all. JAMA 2005;294:2879-88.

5. Witherspoon DJ, Wooding S, Rogers AR, et al. Genetic similarities within and between human populations. Genetics 2007;176:351-9.

6. Bamshad M J, Wooding S, Watkins WS, et al. Human population genetic structure and inference of group membership. Am J Hum Genet 2003;72:578-89.

7. Bonham VL, Warshauer-Baker E, Collins FS. Race and ethnicity in the genome era: the complexity of the constructs. Am Psychol 2005;60:9-15.

8. Collins FS. What we do and don't know about "race," "ethnicity," genetics and health at the dawn of the genome era. Nat Genet 2004;36(Suppl):S13-5.

9. Tang H, Quertermous T, Rodriguez B, et al. Genetic structure, self-identified race/ethnicity, and confounding in case-control association studies. Am J Hum Genet 2005; 76:268-75

10. Centers for Disease Control and Prevention. National Office Public Health Genomics. Family History: Resources and Tools. Atlanta (GA): The Centers; 2007 Available: www.cdc.gov/genomics/public/famhist.htm (accessed 2008 July 31).

11. Department of Health and Human Services. My Family Health Portrait. Washington (DC): The Department; 2007. Available: https://familyhistory.hhs.gov/ (accessed 2008 July 31 ).

12. Manolio TA, Bailey-Wilson JE, Collins FS. Genes, environment and the value of prospective cohort studies. Nat Rev Genet 2006;7:812-20.

13. Guttmacher AE, Collins FS, Carmona R. The family history - more important than ever. N Engl J Med 2004;351:2333-6.

14. Collins FS. The case for a US prospective cohort study of genes and environment. Nature 2004;429:475-7.

15. Schwartz D, Collins F. Medicine, environmental biology and human disease. Science 2007;316:695-6.

16. Williams DR, Jackson PB. Social sources of racial disparities in health. Health Aff (Millwood) 2005;24:325-34.

17. Baxter NN. Equal for whom? Addressing disparities in the Canadian medical system must become a national priority. CMAJ 2007;177:1522-3.

Correspondence to: Dr. Vence L. Bonham, Social and Behavioral Research Branch, Division of Intramural Research, National Human Genome Research Institute, National Institutes of Health, 31 Center Dr., Rm. B1B55, Bethesda MD 20892-2070, USA; fax301480-3066; bonhamv@mail.nih.gov 